\title{
Movimentos sociais e controle social em saúde do trabalhador: inflexões, dissensos e assessoria do Serviço Social
}

\author{
Social movements and social control health worker: \\ inflections, disagreements and advice in Social Service
}

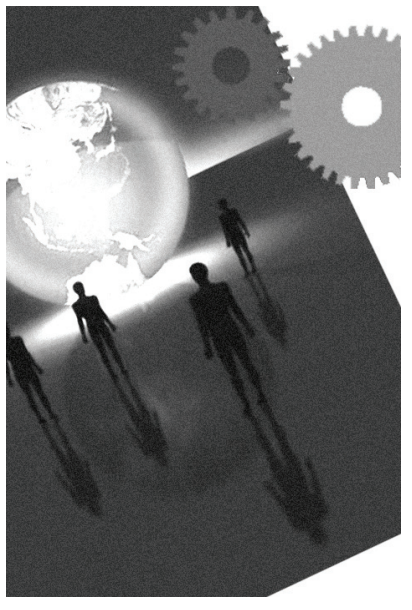

Lúcia M. de B. Freire*

Resumo: O artigo versa sobre as relações entre trabalho, saúde do trabalhador e movimentos sociais em instâncias de controle social e o Serviço Social nessas relações, após 1993 no Brasil. Apresenta novas políticas públicas nesse campo e mediações que determinaram inflexões e retrocessos no controle social democrático, estimulando a cultura autoritária patrimonialista em suas instâncias e em um serviço público de saúde pesquisado. Conclui sobre a necessidade de assessoria democrática participativa entre intelectuais, técnicos e população, exemplificada em práticas de Serviço Social, com apresentação de suas bases teóricas e procedimentos operacionais.

Palavras-chave: Saúde do trabalhador no SUS. Controle social democrático. Relações sociais em instituição pública. Assessoria em Serviço Social.

\begin{abstract}
The article is about the relation among work, workers' health and social movements in social control jurisdiction, and Social Services in these relations in Brazil after 1993. It presents new public policies in this field and mediations which have led to setbacks and variations in democratic social control, stimulating the authoritarian wealthy culture in their bodies and in a public health service searched. The article presents the conclusion that it is necessary participatory democratic advice among intellectuals, technicians and population, as exemplified in the practices of Social Services, with the presentation of their theoretical grounds and operating procedures.
\end{abstract}

Keywords: Health worker in SUS (Unique Health System). Social democratic control. Social relations in public institution. Counsel in Social Services.

* Doutora em Serviço Social pela PUC de São Paulo, professora da Faculdade de Serviço Social da UERJ — Rio de Janeiro/RJ, Brasil, onde desenvolve pesquisas sobre saúde do trabalhador e Serviço Social, liderando o Grupo de Estudos em Serviço Social, Saúde, Trabalho e Meio Ambiente — Gesta. E-mail: gesta. uerj@yahoo.com.br. 


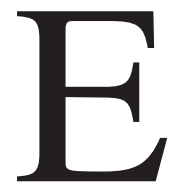

ste texto resulta de pesquisas, assessoria e ensino sobre a relação entre trabalho, saúde do trabalhador, movimentos dos sujeitos integrantes de instâncias societárias e institucionais e do Serviço Social nessas relações. As pesquisas sobre as relações entre essas áreas datam de 1993, após a instalação da reestruturação neoliberal presente nas relações sociais de trabalho, que afetou o movimento sindical em função do desemprego em massa e da contrarreforma do Estado brasileiro, sobretudo no período do segundo governo Fernando Henrique Cardoso. Por sua vez, os bloqueios advindos dessas mediações não eliminaram a resistência desse movimento, mas determinaram algumas inflexões.

A primeira delas, divulgada nos estudos da tese parcialmente publicada (Freire, 1998a; 2003), refere-se ao novo rumo dominante das lutas dos trabalhadores, "numa direção oposta à do estágio fordista-keynesiano, ou seja, de fora para dentro da empresa" (Freire, 2003, p. 50), combatendo e denunciando as situações irregulares de trabalho nas instâncias societárias de controle social e junto a instituições como o Ministério Público do Trabalho. Também, numa percepção de fora das empresas, mais ampla e dialética das mediações, ocupavam espaços de revisão de legislação, assim como estratégias sobre processos universais conforme um sindicalista entrevistado, quando ressaltou a utilização das contradições dentro do próprio interesse capitalista:

[...] o próprio capitalismo, mais uma vez, vai se encarregar de dar as armas, para nós conseguirmos fazer uma mobilização e enfrentamento com relação [à saúde e] às novas ISO [...] a norma de qualidade e a norma de meio ambiente. Porque a atuação mercadológica vai ser o diferencial das empresas. [... e] nenhuma empresa, hoje, quer ser vista nos jornais com notícias ruins sobre a sua atuação [...] a nível de imagem. ${ }^{1}$ (Freire, 1998b, p. 179)

Nesse período até 1997, a saúde do trabalhador parecia constituir um objeto de consenso da classe trabalhadora, conjugando interesses e posições de filiados a facções políticas diferenciadas, como a Central Única de Trabalhadores (CUT) e a

1. Nessa estratégia, este sindicalista se aproxima de Lojkine (1995, p. 310-311, apud Freire, 2003, p. 63), quando considera os impasses de gestão, vividos pelas grandes empresas, entre alternativas de desierarquizar monopólios de comunicação ou preservar as exclusividades de poder que as esclerosam e bloqueiam a criação, reproduzindo "o círculo vicioso dos surdos (os dirigentes) e dos mudos (os executores)". Essa realidade determinou, por sua vez, novas mistificações pela via dos programas de "responsabilidade social", bastante visíveis atualmente e abordados criticamente por Cesar (2006; 2008). 
Força Sindical (FS). Nessas centrais e nos seus filiados, foi verificado que esse tema apresentava pontos comuns de luta, agregados no Conselho Estadual de Saúde do Trabalhador do Rio de Janeiro (Consest-RJ) e comissões municipais, constituindo polo de atração de trabalhadores, contribuindo para "formar quadros de intelectuais orgânicos dessa classe, situando-se como ponta de lança da mobilização de todos os grupos" (Freire, 2003, p. 51), atraindo intelectuais de universidades e centros de pesquisa. O fato também se dava no âmbito nacional, em diversos estados do Brasil, e internacional, como no caso da Confederación Internacional de Sindicatos de la Química, Energia, Minas y Industrias Diversas (Icem) (idem, p. 52). Nesse movimento, houve inclusive alguns avanços na legislação brasileira, obtidos no governo Itamar, quando alguns intelectuais dedicados ao tema ocuparam o Ministério do Trabalho e sua área de Segurança e Saúde, entre eles o Ministro Walter Barelli e a Professora Raquel Rigotto, da UFMG (Freire, 1998a).

A segunda inflexão marcante foi o retrocesso observado de 1998 a 2003, visível principalmente no esvaziamento do Consest-RJ, conforme o gráfico, elaborado a partir das atas das reuniões desse conselho (cf. Freire; Ferreira; Wardine, 2004).

\section{Gráfico sobre as principais atividades do Consest-RJ (1997-2003)}

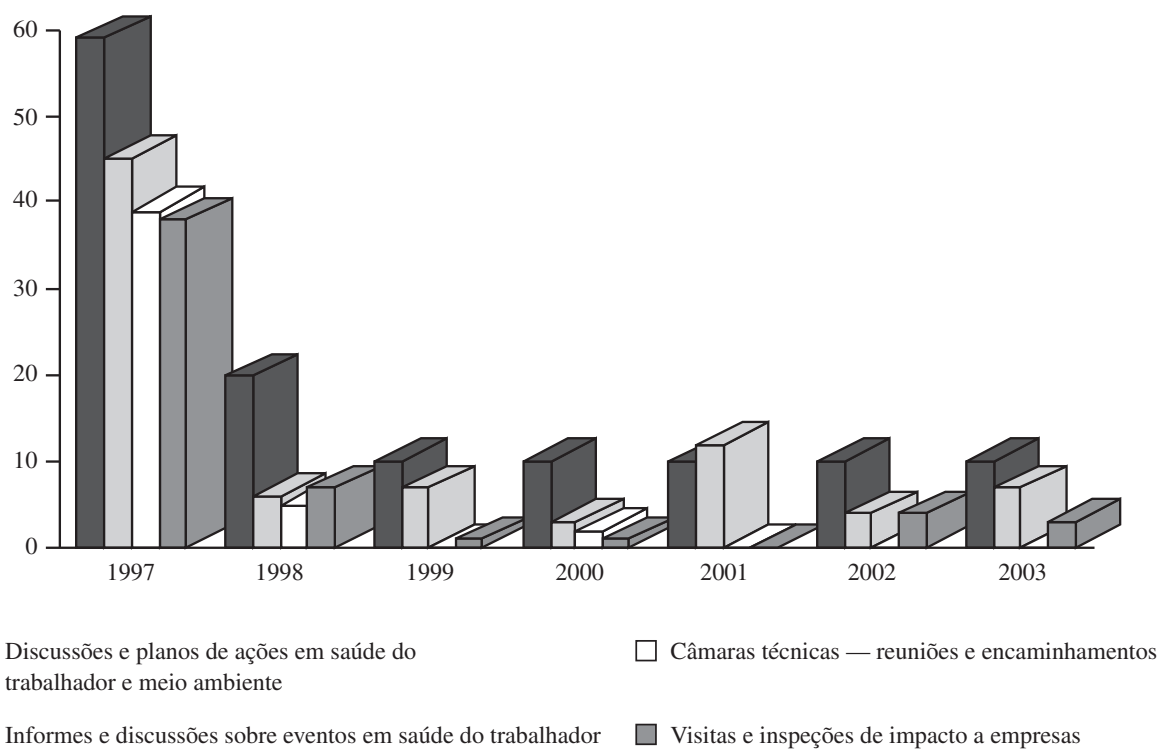


Esse esvasiamento se deu sobretudo nas estratégias e ações efetivas de inspeção e propostas que resultassem em mudança, vinculadas a ações interinstitucionais. A manutenção dos debates deu-se apenas em torno da Rede Nacional de Atenção Integral à Saúde do Trabalhador (Renast) e a constituição do respectivo Centro de Referência no Estado por envolver uma luta por recursos previstos em lei. Houve retraimento progressivo dos sindicatos, ao constatar a falta de respaldo ao conselho para suas ações e, ao mesmo tempo, impedimento às intervenções pelas grandes empresas, inclusive com ações na justiça. ${ }^{2}$ Paralelamente, ocorreu o esvaziamento de profissionais que trabalhavam no Programa, mediante retorno daqueles cedidos por instituições e corte de contratados, que conduziu à extinção de um mecanismo estratégico central para o processo até 1998: o das câmaras técnicas segundo ramo de produção. Sem essas câmaras, a análise dos casos e o planejamento das estratégias ficaram comprometidos, refletindo-se na ausência dos sindicalistas nas reuniões do conselho e na relativa superficialidade no trato das questões e ações ali abordadas. De outro lado, ainda foram intensificados processos de cooptação de trabalhadores, prefeitos e comunidades, antes associados à luta contra as agressões ao meio ambiente, por intermédio dos denominados programas de "responsabilidade social" de empresas, mascaradores da realidade e despolitizadores. ${ }^{3}$

A terceira inflexão, em parte decorrente da anterior, foi marcada pelo dissenso entre os integrantes das instâncias de controle social, verificado principalmente a partir de 2005, no período da organização da III Conferência Estadual de Saúde do Trabalhador do Rio de Janeiro (Cest-RJ). A partir de então, foram observadas contradições que contrariam os princípios e diretrizes da Reforma Sanitária, estabelecidos desde a Constituição Federal de 1988 e nas Constituições estaduais de vanguarda, como a deste Estado. Elas revelaram a incorporação da velha cultura política patrimonialista por um segmento desses integrantes, em oposição à cultura do movimento sindical presente anteriormente.

Dialeticamente, essa contradição se tornou mais visível após a recomposição dos mecanismos de controle social democrático, observada a partir de 2003, no início do primeiro governo Lula, quando se verificaram novos estímulos à revitalização dessa política, sobretudo por meio do Ministério da Saúde, com destaque para duas medidas que caracterizam um momento de reestruturação diferenciado dos anteriores. A primeira foi a retomada das Conferências de Saúde do Trabalha-

2. Maiores detalhes e aprofundamento sobre essas ações são encontrados em Vasconcellos (2007).

3. Sobre este processo, ver Porto (2000) e a análise teórica de Cesar (2006). 
dor, depois de onze anos, articuladas com as Conferências de Saúde nas três instâncias governamentais, juntamente com a multiplicação desse instrumento e dos Conselhos Municipais de Saúde, mais a implantação de Conselhos Gestores de Saúde e desenvolvimento de Comissões de Saúde do Trabalhador nos Conselhos de Saúde. A segunda referiu-se à efetivação da Renast, por meio de liberação dos recursos a ela destinados.

A partir de 2005, uma série de mudanças marcou a fase de reestruturação do Programa de Saúde do Trabalhador (PST) no Rio de Janeiro. ${ }^{4}$ Porém a mudança mais impactante, reveladora da contradição na classe que vive do seu trabalho e das consequências do retrocesso após 1997, apresentou-se no dissenso provocado pelo embate entre a cultura política tradicional, inserida em segmento do próprio controle social em saúde, e a cultura da luta sindical e formação política em saúde do trabalhador, desenvolvida anteriormente no Consest-RJ. Esse dissenso é contraditório com a perspectiva de que ambas as representações constituem faces da mesma expressão da questão social e com a realidade da população constituir-se majoritariamente de trabalhadores.

O centro da discórdia, que tornou mais perceptível esse dissenso, localizou-se na competição pela hegemonia nos espaços políticos de controle social, revelada muito intensamente no Rio de Janeiro. Isto se deu, em parte, em virtude de ser o único estado da Federação a ter constituído, antes mesmo do Conselho Estadual de Saúde (CES), o Conselho Estadual de Saúde do Trabalhador (Consest-RJ), com singularidades especiais, destacando-se entre elas a do funcionamento como um colegiado interinstitucional e intersindical e a vigilância dos locais de trabalho. ${ }^{5}$ Porém, exatamente essas diferenças, que expressavam o maior avanço político, democrático e da extensão da vigilância aos locais de trabalho, incomodaram os integrantes do CES, evidenciando um grande distanciamento nos processos de formação política entre os sujeitos de ambas as instâncias. Tal distanciamento

4. Entre elas, a Secretaria de Estado de Saúde, no novo governo estadual, em 2007, recebeu a incorporação da Defesa Civil, atestando a preocupação desse governo com a questão da segurança. Nesse processo, o PST ascendeu ao status de Divisão de Saúde do Trabalhador (DST). Essa mudança, junto com a aparente valorização do antigo programa, implicou um maior controle burocratizado das ações e processos, num retrocesso administrativo contrastante com a flexibilidade e o ambiente propício à criatividade até 1997 . O fato também demonstra a permanência da velha burocracia a serviço do controle do poder, oposta ao discurso da flexibilização e do gerencialismo neoliberal, mais voltados para a redução de direitos.

5. As características exemplares desse Conselho são apresentadas em Vasconcellos e Ribeiro (1994; 1997), Freire (1998a; 2003) e Vasconcellos (2007). 
contribuiu não apenas para a extinção do Consest-RJ, por deliberação da III Conferência Nacional de Saúde do Trabalhador (CNST), efetivada em 2006, mas uma competição destrutiva, que impediu, até o primeiro semestre de 2009, o Estado do Rio de Janeiro de ter efetivamente uma Comissão Intersetorial de Saúde do Trabalhador (Cist) no CES desse estado, prevista na estrutura de controle social e existente em vários outros conselhos. Portanto, de uma exceção positiva de ser o único estado com dois Conselhos (um deles especializado e com representação no CES), o Rio de Janeiro tornou-se a exceção negativa quanto ao controle social em saúde do trabalhador. ${ }^{6}$

Após a organização da III Cest pela coordenadora do então PST/RJ, por se tratar de um evento focado na saúde do trabalhador, o Consest-RJ sofreu retaliações mais ostensivas, sendo proposta a denúncia para sua extinção ao secretário de estado de Saúde. ${ }^{7}$ Entretanto, a pressão paralela dos seus conselheiros junto àquele secretário resultou na sua manutenção, decidida até a III Cest. ${ }^{8}$ Nessa Conferência, inclusive, foi aprovada uma moção pela manutenção do Consest-RJ, por sua constituição histórica, ampla cobertura institucional, metodologia desenvolvida e vigilância em saúde do trabalhador. Essa resistência, no entanto, não foi suficiente para ultrapassar as barreiras.

O clima tenso entre os dois conselhos estaduais se intensificou em função do jogo de poder de delegação para a III Conferência Nacional de Saúde do Trabalhador, na qual muitos conselheiros do Consest-RJ ficaram de fora, devido ao número restrito de vagas de delegados e sua escolha pelo CES-RJ. Esses conselheiros se sentiram desprestigiados por não irem credenciados como tal, sem direito a voto, sendo, no final dessa III CNST, precipitada a dissolução do Consest-RJ. Questões de fundo, identificando as diferenças decorrentes das especificidades do campo do trabalho, não compreendidas ou respeitadas pelos delegados do CES-RJ, também

6. Vasconcellos (2007) destaca, a esse respeito, a considerada "aberração" da existência de dois conselhos estaduais, desde a II CNST, sendo porém aceita, em face do significado histórico e consenso quanto às diretrizes comuns. Todavia, no momento histórico de 2005, o consenso transformara-se em conflito com disputa de poder.

7. O marco da animosidade se deveu à prioridade do CES em comandar a organização de eventos, como meio ideológico de hegemonia e em razão da visibilidade proporcionada, assim como condições de viagens e de escolha e credenciamento de delegados, característicos do patrimonialismo.

8. Nessa ocasião, ocorreu certo revigoramento desses conselheiros, porém algumas perdas se tornaram irrecuperáveis no Consest-RJ. Entre elas, a das câmaras técnicas, cujo retorno havia sido buscado, mas não se tornou viável, sobretudo por causa do quantitativo insuficiente de técnicos de apoio e o deslocamento dos pesquisadores voluntários que haviam se engajado em outros projetos e tarefas. 
foram pontos de embate nessa Conferência Nacional. A primeira delas foi a defesa do adicional de insalubridade pelos delegados do CES-RJ, que, ao mercantilizar a saúde dos trabalhadores, contrariou um dos princípios historicamente defendidos desde as Semanas de Estudos da Saúde do Trabalhador (Semsat), de 1979 a 1988, sintetizados no lema "saúde não se troca por dinheiro" (Diesat, 1989). A segunda questão foi a defesa do tripartismo não somente nos conselhos, conforme a Resolução n. 33 do Conselho Nacional de Saúde (CNS), mas também nas Cist, chocando-se com uma das singularidades do Consest-RJ, que consistia no caráter bipartite na sua composição. Isto para melhor desempenhar o papel de vigilância das condições de trabalho, não sendo composto por representantes de empresários ou de dirigentes de instituições, mas por representantes de sindicatos/Centrais Sindicais e de instituições de excelência relacionadas à saúde do trabalhador nesse estado. ${ }^{9}$

Além dessas disparidades de conhecimento, que implica formação e trajetória histórica de lutas, parece predominar a cultura política patrimonialista tradicional, como de muitas comunidades brasileiras, locais de origem da maioria das lideranças populares que compõem o CES-RJ, já ressaltada na prioridade ao controle dos pequenos mecanismos de poder, como o do destino da verba para eventos e viagens, reproduzindo as disputas no país. ${ }^{10}$

A mediação central para o impasse na constituição da Cist no CES-RJ encontra-se no fato de ter sido assegurado, no Ato Normativo da extinção do Consest-RJ, que essa Comissão teria a mesma composição. Assim, ela foi reproduzida no seu Regimento Interno, elaborado desde 2006, mantendo praticamente todo o conteúdo do extinto Conselho, com alguns ajustes, além da garantia de assento de seus mem-

9. Após repetidos debates posteriores, essa posição do Consest-RJ foi mantida no Regimento Interno da Cist/ERJ, concluído apenas em julho de 2008.

10. Esses processos se inserem em outras manifestações de problemáticas culturais como as apontadas por Bravo (2001, p. 59) sobre os Conselhos de Saúde em geral, a seguir: a) a falta de respeito às deliberações dos conselhos e conferências pelo poder público executivo, nos três níveis; b) a manipulação ou repressão do efetivo controle social por esse poder, em aliança com interesses particulares privados; c) a falta de respeito às leis que regulamentam o funcionamento dos conselhos, em alguns deles; d) a priorização da burocratização das ações no funcionamento dos conselhos; e) necessidade de repensar a dinâmica dos conselhos, para maior envolvimento dos participantes; f) o posicionamento tímido em relação à agenda neoliberal pelos conselhos e conferências; g) a falta de plena consciência da existência dos conselhos pela sociedade civil organizada; h) a pouca contribuição à democratização da esfera pública pelos conselhos em geral; i) exercício de chantagem institucional pelo Poder Executivo, ao ameaçar prejuízo para a população no caso de as propostas apresentadas serem contestadas pelos conselheiros; j) falta de soluções jurídicas mais ágeis quando da necessidade de se defrontar com o Executivo. 
bros nessa Cist. ${ }^{11}$ Porém, a questão da composição provocou a não conclusão desse regimento, prolongando-se a discussão por todo o ano de 2007 e impedindo a regulamentação desse item. Como solução para sua aprovação, em janeiro de 2008, ele foi colocado genericamente nas disposições transitórias. Com todo esse dissenso, o processo de instalação dessa comissão no Rio de Janeiro ocorreu apenas em janeiro de 2009, não tendo sido efetivado o seu funcionamento em todo aquele semestre. Na própria reunião de instalação formal da Cist/ERJ, as disputas foram verbalmente reproduzidas, com tensos debates, inclusive sobre a participação da Federação das Indústrias do Rio de Janeiro (Firjan), que se manteve em razão das entidades formadoras e culturais do Sesi e Senai. ${ }^{12}$

Idênticas dificuldades foram identificadas em relação à implantação da Renast. Com seus Centros de Referência (Cerest), sigla que substituiu a do Cresat ou Nusat, essa rede é apresentada como o mais importante mecanismo para recompor a política de saúde do trabalhador após 1998. Entretanto, como os espaços de controle social e do SUS como um todo, ela também revela as contradições entre as concepções, princípios e diretrizes de saúde do trabalhador e sua efetivação, ao mesmo tempo evidenciando as dificuldades da cultura da gestão pública no Brasil e seu exercício, sobretudo no sentido democrático entre as suas múltiplas instâncias e níveis.

A Renast foi concebida num primeiro formato, em 2000, no âmbito da Secretaria de Políticas de Saúde (SPS/MS), pela sua Área Técnica de Saúde do Trabalhador (Cosat), com o enfoque sistêmico articulado ao SUS. Esse enfoque é apresentado por Vasconcellos (2007, p. 24-38) como uma das premissas de sua tese, no sentido do "comando político com unificação de interesses e diretrizes de tudo aquilo que diz respeito direta ou indiretamente à saúde, [não passando] pela absorção de estruturas ou órgãos, mas somente pela articulação e inteligência programática [...]" (Idem, 2007, p. 24-25). Isto por considerar essa ideia impregnada na própria definição do SUS e na sua lei orgânica, sendo esse papel previsto inclusive nas comissões intersetoriais, que inclui a saúde do trabalhador como instância "aglutinadora de políticas públicas intersetoriais para dar conta de prover saúde à população brasileira, em todas as suas interfaces Estado-sociedade” (Idem, p. 26).

11. Essa Resolução foi assinada pelo secretário de Saúde do governo Rosinha Garotinho, em agosto de 2006, e trata da extinção do Consest e de seus integrantes na futura Cist Estadual.

12. Nessa reunião também foi discutida a ausência de alguns sindicatos e da maioria das instituições de ensino e pesquisa historicamente integrantes do movimento de saúde do trabalhador no Rio de Janeiro e do Consest-RJ, como a Ensp/Fiocruz e outras universidades, por problemas de envio da documentação em curto prazo, no período de férias, com presença apenas da representação da Uerj. 
Porém, segundo esse autor, existe uma "paralisia do sistema", ou sua não efetivação, em virtude de "conflitos políticos, corporativos e institucionais [...], tão mais intensos quanto mais forem assumidas as prerrogativas sistêmicas pelos gestores em cada nível de gestão [tomadas como] ingerência na perspectiva política" (Idem). Nesse sentido, ele afirma a necessidade de "uma retaguarda de poder que só o Estado, do alto da macropolítica [...] é capaz de garantir" (Idem, p. 26-27). Ele afirma também a sua viabilidade devido à solidez estrutural do SUS e de sua "rede de vasos comunicantes de instâncias de controle, pouco sujeitas às variações conjunturais" (Idem, p. 27), e "o desafio da transposição da gestão para além do setor propriamente dito, acompanhando os pactos setoriais até o nível mais elementar de gestão [em uma] transição para o trans" (Idem, p. 35-36).

Nesse sentido, a concepção da Renast de 2000 afastava-se de uma assistência especializada de um SUS paralelo para o trabalhador, mas se dirigindo à capacitação desse sistema para inserir a relação saúde-trabalho no seu atendimento, cuja demanda majoritária é constituída de trabalhadores. Sua direção principal era a de ser "um polo irradiador de cultura, núcleo de inteligência e supervisão, com foco na capacitação e na vigilância, entre outros" (Vasconcellos, 2007, p. 248). Essa concepção partiu da revisão crítica dos Programas de Saúde do Trabalhador (PST) e seus centros de referência, que foram perdendo a importância com o retrocesso após 1997. Depois de cumprir o significativo papel de contribuir "para a construção de uma atenção diferenciada à saúde dos trabalhadores no SUS, como expressão da luta organizada dos trabalhadores por melhores condições de vida e trabalho e da ação de tutela da saúde dos cidadãos pelo Estado" (Dias e Hoefel, 2005, p. 822), eles foram se tornando cada vez mais isolados e marginalizados "das estruturas e políticas do SUS, conformando os 'guetos da Saúde do Trabalhador', além de uma fraca articulação intersetorial" (Idem). Muitos deles, conforme Vasconcellos (2007, p. 249) "pareciam com hora marcada para morrer, como, aliás, aconteceu com vários programas pelo Brasil adentro", apesar de ter havido "intenso ingresso de novos profissionais e uma enorme participação do tema da saúde do trabalhador em congressos e seminários de saúde" (Idem). Também foi diagnosticado, no Encontro Nacional de Saúde do Trabalhador (ENST), realizado em 1999 com o objetivo de reconstrução dessa política, o isolamento entre os PST/Cerest e a ausência de intercâmbio técnico e científico e de diálogo político-institucional. O caso singular do PST/SES-RJ confirma essa realidade, tendo se mantido, a partir de 2001, em torno do interesse na Renast, a despeito de sua construção histórica e continuidade de suas diretrizes. 
Porém, os dificultadores para a realização desse sistema, entre eles "as questões, desde sempre, emergentes e nunca resolvidas na relação saúde-trabalho" (Vasconcellos, 2007, p. 34), parecem situar-se na relativa incompatibilidade entre a perspectiva sistêmica - na sua harmonia funcional perfeita, presente e adequada no organismo humano, nas máquinas e na concepção de sistemas organizacionais como o SUS - e a dialética conflituosa das relações sociais, nas quais se inserem os interesses econômicos, a cultura política, suas oportunidades objetivas e alianças. Nessa realidade:

No final do ano de 2002, uma oportunidade política, surgida no âmbito da Secretaria de Assistência à Saúde do Ministério da Saúde, permitiu a criação da Rede Nacional de Atenção Integral à Saúde do Trabalhador (Renast). Apesar das críticas e dos desencontros institucionais observados no processo de elaboração desse instrumento, em particular a ênfase nas ações assistenciais, a portaria foi apoiada pelos profissionais e técnicos dos CRST e setores do movimento dos trabalhadores, que reconheceram na iniciativa uma oportunidade de institucionalização e fortalecimento da Saúde do Trabalhador, no SUS. Pela primeira vez, seria possível contar com um financiamento extrateto das ações, vinculado à operacionalização de um Plano de Trabalho de Saúde do Trabalhador, em nível estadual e municipal. (Dias e Hoefel, 2005, p. 824)

Assim, em função, inclusive, da oportunidade do aporte considerável de recursos pelo financiamento "extrateto", houve uma segunda construção, elaborada por outra área técnica paralela de outra Secretaria do MS, a de Atenção à Saúde (SAS). Esse financiamento, porém, implica a rubrica da assistência de alta complexidade, que mantém os problemas da atenção paralela. Após resistência em prol da discussão democrática da proposta pelos demais sujeitos coletivos engajados no objetivo, entre eles a Área Técnica [antiga Coordenação] de Saúde do Trabalhador (Cosat) do MS, a CUT e o Conselho Nacional de Secretários da Saúde (Conass), segundo Vasconcellos (2007, p. 245-247), foi obtida a reelaboração emergencial da Portaria. ${ }^{13}$ A síntese buscada entre a concepção original e a segunda, agregando estratégias da primeira, não retirou, porém, de acordo com esse autor, "o foco do

13. Assim, a RENAST foi instituída pela Portaria n. 1.679 do MS, de 19 de setembro de 2002 (Brasil, 2002) e, posteriormente, ampliada pela Portaria n. 1.068 do MS, de 4 de julho de 2005 (Brasil, 2005a) e n. 2.437/2005 do MS (Brasil, 2005b), que a regulamenta. Esta última também resultou das Resoluções das III Conferência Nacional de Saúde do Trabalhador. Das forças políticas da Engenharia nesse evento provêm também a introdução do termo segurança na Política Nacional de Segurança e Saúde do Trabalhador (PNSST), como se esta não estivesse implícita no conceito de saúde do trabalhador, assim como a nutrição, a psicologia, o Serviço Social e outras áreas. 
assistencialismo", que comprometeu a proposta inicial. Com essa "solução" conciliatória, a despeito dos problemas mantidos, houve avanços para a área. Por esse motivo, ela obteve apoio, sobretudo pelos PST/Cerest já estruturados, habituados a ações sempre contra-hegemônicas, com esforço para superar a ausência de recursos financeiros, materiais e de pessoal, que obtiveram possibilidade de revitalização. Entre os avanços, são assinalados:

a ampliação dos centros pelo país; a capacidade de possuir dotação orçamentária própria; desdobramentos na sua condução como a elaboração de protocolos de agravos e procedimentos; o estímulo ao intercâmbio entre os centros; o desencadeamento de processos de capacitação; e, entre outros, a manutenção de um status permanente de mobilização de seus componentes. (Vasconcellos, 2007, p. 254)

O processo de construção da Renast, portanto, "representou o aprofundamento da institucionalização e do fortalecimento da saúde do trabalhador no âmbito do SUS, reunindo as condições para o estabelecimento de uma política de Estado e os meios para sua execução" (Brasil, 2006a, p. 19-20). O seu principal objetivo é o de "integrar a rede de serviços do SUS, voltados à assistência e à vigilância para o desenvolvimento das ações de saúde do trabalhador" (Idem, p. 26).

Segundo esse documento, as atribuições principais dos Cerests são: capacitar a rede de serviços de saúde; assessorar e apoiar as investigações de maior complexidade e a estruturação da assistência de média e alta complexidade para atender aos acidentes de trabalho e agravos contidos na lista de doenças relacionadas ao trabalho e aos de notificação compulsória, vinculados a processos de trabalho, inclusive com realização de convênios de cooperação técnica, e, com esses dados, subsidiar a formulação de políticas públicas em saúde do trabalhador. Porém, por não terem sido superadas as questões de fundo, a Renast corre o risco de manter seus centros como "ambulatórios especializados" (Vasconcellos, 2007). Este aspecto parece situar-se basicamente em um dos próprios processos de trabalho atribuídos no Modelo de Projeto do Cerest a ser habilitado (Brasil, 2006a, anexo 1). Consiste em "ações assistenciais individuais, como atendimento, acolhimento do usuário, consultas, exames e orientações". Nessas atribuições também seriam incluídas as notificações dos acidentes de trabalho ali atendidos.

Assim, na captação de mediações em torno da construção da Renast, que manteve procedimentos em duas direções - a da capacitação e assessoria às unidades do SUS e a do atendimento direto - é revelada a fragmentação institucional e a dificuldade da interação democrática na elaboração das políticas públicas no 
Brasil, misturando-se a outros elementos históricos contraditórios. Entre esses processos, destacam-se os seguintes, que contrariam os princípios democráticos e interinstitucionais do SUS (cf. Vasconcellos, 2007, p. 253), confirmando a cultura patrimonialista da gestão pública: a) conflito entre as diretrizes dos múltiplos órgãos da União que normatizam e controlam as atividades; b) dificuldade de integração entre gestores estaduais e municipais e respectivas instâncias de controle social, na concepção, planejamento e normatização da matéria, também ausente em relação à Comissão Intergestores Tripartite (CIT) e ao plenário do CNS.

Portanto, os avanços e os problemas mantidos, a partir da própria regulamentação, expressam as faces dialéticas da questão, por manter as atividades assistenciais nos Cerests. Ampliaram-se as possibilidades, porém com dificuldades de atingir o objetivo básico sistêmico de "introjetar a saúde do trabalhador em todas as práticas de saúde, considerando a transversalidade da categoria trabalho e a inclusão das relações saúde-trabalho como determinante protagônico em saúde pública" (Vasconcellos, 2007, p. 253). Trata-se da realidade social contraditória impondo-se além das utopias sistêmicas, na qual as relações sociais implicam interesses circunstanciais, culturas e poderes historicamente construídos, que se fixaram ao longo dos anos de construção dos programas municipais e núcleos de saúde do trabalhador. Parece-nos que a superação relativa de tais impasses, na dimensão local, teria melhores possibilidades por meio de debates em encontros, nos quais fossem consideradas essas experiências, com um plano de transição construído em conjunto. Nesse sentido, foi significativa a entrevista com dois técnicos de Cerests do estado do Rio de Janeiro, ao colocar a realidade do cotidiano desses centros. Neles se apresentavam como principais processos, além das exigências duplas da legislação: a) a dificuldade e o tempo necessário para capacitação dos trabalhadores do SUS para atender às necessidades exigidas para elucidação das situações que envolvem o trabalho, complexas e diferenciadas; b) urgência para atender a essas situações, muitas vezes implicando direitos/benefícios ou punições em relação ao trabalho, afastamentos e vigilância nos locais de trabalho; c) a natural busca do Centro pelos trabalhadores, sobretudo quando conhecedores do atendimento diferenciado, ainda por um longo tempo não acessível nos serviços do SUS. Na realidade, existe a necessidade de um processo de transição de médio prazo, que exige investimentos de várias naturezas, sobretudo de interação entre os técnicos especializados e entre os diversos níveis de serviços do SUS, a partir da realidade dos executores, com participação democrática no planejamento, decisões, normas e rotinas entre ambos os serviços. 
Em meio a esses processos, somam-se contradições na efetivação da Rede, envolvendo profissionais, dirigentes dos campos da saúde do trabalhador e da saúde e dos respectivos integrantes das instâncias de controle social-democrático. Essas contradições e dissensos em torno da consolidação da Renast no Rio de Janeiro também se vinculam às representações de poder, que, no caso, envolvem ainda o dinheiro público disponibilizado para essa rede. Elas são visíveis principalmente na priorização particular dos objetivos, que devem ser integralizados, mas que se fragmentam nas duas direções também ligadas a diferentes culturas dominantes. Como já apontado, a realidade impõe a mistura dessas duas direções, na difícil transição, cuja efetivação somente será possível com a superação de posições pessoais, em programas que estimulem a abertura e a motivação sobre a articulação entre os profissionais da rede de saúde do trabalhador e da rede de serviços do SUS.

No campo das instituições de saúde, as pesquisas desta autora têm verificado contradições semelhantes em torno das condições de saúde dos trabalhadores da saúde, necessárias para um atendimento de qualidade aos usuários e aplicação das políticas do SUS, entre elas a Política Nacional de Humanização (PNH, cf. Brasil, 2006b). Entre as mediações no espaço institucional, foram localizadas contradições nas relações de trabalho em um Hospital Público Universitário (HPU) investigado, que também remetem às derivações da herança patrimonialista e burocrática da gestão pública do Estado brasileiro (Batista, 1999), ${ }^{14}$ agravadas com as prescrições gerencialistas da política neoliberal da citada contrarreforma. Essas mediações dificultaram o avanço da PNH, da política de saúde do trabalhador e da constituição do conselho gestor, contraditórias com práticas distanciadas dos seus princípios de controle social, verificadas nos processos a seguir.

O primeiro deles é o desenvolvimento da PNH identificada com poderes particulares, no interior do HPU, dificultando a formação de um projeto comum que articule seus diversos setores. Em consequência, ocorre a centralização de decisões, sem a constituição de um colegiado que contribua para a formação de uma vontade coletiva. Com isso, há ausência de participação dos trabalhadores e usuários na análise das condições desse hospital, resultando na estagnação do processo, que se fragmenta em projetos particulares de grupos, ficando sua execução sob a responsabilidade de cada um deles.

14. O autoritarismo patrimonialista sobrevive a despeito de processo eleitoral da direção do hospital, que é uma conquista das universidades públicas no Brasil, mantendo porém os arranjos políticos dessa sociedade. Mesmo assim as possibilidades são renovadas periodicamente, com a relativa autonomia associada à estabilidade dos concursados, o que não ocorre na gestão privada. 
Paralelamente, amplia-se a desmotivação quanto ao trabalho, com várias faces, iniciando-se pela falta de reconhecimento, inclusive da equipe voltada para a saúde do trabalhador, existindo entraves burocráticos que dissolvem a relativa autonomia de alguns e desestimulam o trabalho criativo. Essas injunções exemplificam cargas sociais que afetam a saúde física e psíquica dos trabalhadores, inclusive dos intelectuais, assim como sua sociabilidade e comportamento de sujeitos políticos. A concepção de carga social foi desenvolvida por esta autora, com base nos conceitos de desgaste da saúde e cargas negativas de trabalho, de Laurell e Noriega (1989), distinta de risco, ao destacar um processo permanente provocador do desgaste pelo trabalho. Às suas várias origens - físicas, químicas, biológicas e mecânicas, geradoras de cargas fisiológicas e psíquicas, na dinâmica interna dos indivíduos, acrescento:

[...] a carga social [de origem externa e interna], na sua dimensão particular do local de trabalho (coexistindo, em relação, com a dimensão da universalidade societária), ela é construída e reproduzida no próprio processo de trabalho, expressando-se em fatos como desigualdade, autoritarismo, privação de poder de enfrentamento direto, coerção, chantagem e outras decorrentes da posição social na divisão, processo e organização do trabalho, incluindo-se as questões de gênero, idade e etnia, embutidas nas demais. Ela se revela sob todas as formas de "violência simbólica", implicada nas relações sociopolíticas dos sujeitos em face da realidade deste processo, o que é evidenciado na pesquisa (Freire, 1998a; 2003, p. 41). ${ }^{15}$

Esse tipo de carga foi constatado no HPU, em entrevistas realizadas desde 2005 e com o grupo focal constituído por assistentes sociais da equipe de saúde do trabalhador em 2008. Esse processo, alimentado pela cultura dominante de gestão autoritária e centralizadora versus relações de submissão e apatia, provoca uma "anergia institucional" (Barbier, 1985) ${ }_{16}^{16}$ similar à denominada síndrome de burnout, desenvolvida pela Psicologia Social, ou "apagamento da chama", em um processo de "autoalienação social" provocado por acúmulo de desgaste sociopolítico. Esse processo foi constatado nas dificuldades de mobilização para projetos e movimentos como os de greve ou pressão junto aos poderes constituídos, inclusive em militantes históricos na instituição, em virtude de sucessivos atos indiretamente puni-

15. Ela está, portanto, relacionada com a organização social do trabalho, apresentando afinidade com os estudos de psicologia social que vinculam esta organização ao desgaste mental dos trabalhadores, assim como ao "assédio moral", desenvolvido no direito e integrante de legislação específica.

16. A anergia é colocada no sentido contrário ao de energia, obstando o movimento e mudanças. 
tivos, como descredenciamento de representatividade em instâncias externas e comissões de inquérito indevidas. Também as análises sobre o movimento sindical no HPU têm sinalizado que as ações políticas nele desenvolvidas, avançadas quanto aos direitos e lutas salariais, têm se detido mais nessas lutas e em um plano de cargos e carreiras e menos nos processos cotidianos de trabalho e nas condições que agridem a sua saúde.

Nesse sentido, a agressão à saúde dos trabalhadores do HPU tem sido evidenciada em diversos períodos (cf. Wardine, 2004; Costa, 2006; Coutinho, Mello e Freire, 2009). Seu adoecimento pelas cargas negativas de trabalho tem maior incidência nos auxiliares de enfermagem, como categoria mais subalternizada, constituída predominantemente de mulheres, que, em sua maioria, desenvolvem triplas jornadas de trabalho. Neles se cruzam os diversos níveis de subalternidade que expressam a desigualdade: a da formação, a das condições de vida em geral e de trabalho, a partir do nível salarial e de todas as suas cargas negativas, físicas, psíquicas e sociais. Esse processo tem se ampliado com os anos, conforme dados referentes à "readaptação funcional". ${ }^{17}$ Nesse sentido, com a contrarreforma do estado oficializada desde 1995, que trouxe a ampliação das subcontratações, é possível que, a médio prazo, seja produzido um maior número de trabalhadores dessa categoria desgastados e também descartados, sem a oportunidade de readaptação com o vínculo de trabalho, restando somente o processo de reabilitação profissional previdenciária, de recolocação mais difícil como trabalhador.

Também foi verificado retrocesso em programas da área de saúde do trabalhador no HPU, com fragmentação do trabalho da equipe multidisciplinar, subordinada à perspectiva burocrática de seguir a rotina prescrita e compartimentada. Nesta ótica, inexiste a transdisciplinaridade, ou seja, os pontos comuns a toda a equipe, que "se reflete na tendência à manutenção de ilhas de saber/poder e no receio diante da possibilidade de construir [...] [vínculos] entre as diversas áreas de conhecimento" (Ferreira, 2007, p. 15). Segundo essa autora, essa dinâmica, contrária às diretrizes da política de saúde do trabalhador, determina que a prática dos profissionais voltados para a execução dos Exames Periódicos de Saúde (EPS) junto aos trabalhadores do HPU, em seu conjunto, não apresente resolutividade, passando a constituir um

17. A readaptação funcional consiste no direito conquistado, presente no Estatuto dos Funcionários Públicos, de mudança de função, dentro ou fora do setor de lotação, devido a uma situação comprovada de limitação no trabalho em virtude de desgaste de sua saúde relacionado ao trabalho. 
trabalho burocrático, sem implicações efetivas no sentido de garantir a melhoria das condições de trabalho e de prevenir doenças e/ou seus agravos.

Como mediação mais ampla e recente, situa-se o citado desmonte da esfera pública, oficializado na contrarreforma do Estado de 1995, passando pelos seguintes processos: as restrições do financiamento às instituições públicas, com desrespeito à legislação e repasse a criações híbridas dessa contrarreforma, como as organizações sociais, atualizadas nas fundações públicas de direito privado, ambas resultando em ações de inconstitucionalidade, porém avançando no processo de privatização do público; ${ }^{18}$ os impactos da reestruturação produtiva no serviço público e em seus servidores, refletidos na precarização dos vínculos e das condições de trabalho, estagnação salarial e escolha de chefes com características patrimonialistas, que mantêm a submissão; a manipulação da classe dominante sobre a opinião pública no reforço da imagem negativa do funcionário público, desvalorizado, com consequente perda de status profissional diante da sociedade. Nesse conjunto, consolidou-se a desigualdade entre os trabalhadores, contraditória com a PNH, que resulta em processo de seu descrédito, como apresentado por dois entrevistados subcontratados, ao questionarem, num demonstrativo de carga social de trabalho:

tem que se investigar por que a pessoa, depois de duas horas [de trabalho], está irritada; o que fazer quando, ao final de cada dia, as contratadas já não suportam mais trabalhar com a médica, que fica gritando? É possível humanizar o trabalho mantendo o vínculo de contratado, por exemplo? ${ }^{19}$

Em meio a essas contradições, o controle social no âmbito da instituição investigada apresentou-se praticamente nulo, com investimentos pontuais. Esses poucos investimentos, por sua vez, encontraram barreiras na referida anergia, autoritarismo e demais condições precárias, incluindo a ausência de tempo para essa atividade, por sobrecarga de trabalho e falta desse objetivo no planejamento.

18. Esse avanço é devido à correlação desigual de forças, manifestado nos seguintes processos: o uso autoritário e cooptado na institucionalização das contrarreformas; o domínio conservador dos meios de comunicação, com a fetichização da competitividade e do individualismo e a demonização dos espaços públicos; a degradação da educação, da saúde e de outros serviços públicos, por insuficiência do investimento proporcional à demanda, ampliada pelo direito universalizado a ambas, sem a obrigatoriedade dos recursos correspondentes nos orçamentos.

19. O contratado nesse hospital, por ser público, significa um vínculo de contrato temporário, inferior ao funcionário concursado estável, sem uma série de direitos. Em 2008, já existia uma proporção de 12,5\% de contratados, ou seja, um para cada sete estatutários. 
Existe, portanto, tanto no espaço societário como no institucional, um retrocesso que reforça a manutenção de relações sociais patrimonialistas e de forma de gestão autoritária, com disputa de poder e bloqueios ao exercício democrático de controle social pela população trabalhadora, presente nas políticas do SUS e de saúde do trabalhador. Esses processos confirmam os estudos de que a ideologia hegemônica adapta e coopta as leis e a cultura de modo conveniente à reprodução do capital. Desse modo, a reflexão da realidade além das aparências fica obstada, mais ainda para a grande maioria da população, preocupada com os afazeres da vida cotidiana. Conforme Netto (1987, p. 66), com base em Lukács, as determinações fundamentais da cotidianidade são a heterogeneidade, a imediaticidade e a superficialidade extensiva, impregnada da ideologia dominante. Nesse sentido, a atual conjuntura desfavorável tem fortalecido uma cultura que põe grande parte da população alheia à possibilidade de participação, de modo consciente, das deliberações e decisões que afetam a vida social. Isto, em grande parte, por desconhecimento de seus direitos, por falta de tempo e condições de conhecê-los, em face da luta cotidiana pela sobrevivência em condições de trabalho extensivo e de vida precária (incluindo distância do local de trabalho).

Nesse cotidiano, a capacidade de luta do trabalhador fica reduzida com a mutilação do corpo e da mente, agravada pela ameaça do desemprego, intensificado na reestruturação neoliberal, consequentes perdas de direitos sociais e aumento da carga social no trabalho, com submissão a agressões a sua saúde. Assim, esse tipo de carga incide não apenas sobre a saúde dos trabalhadores, desgastando sua condição física, psíquica e social, degradando suas condições de vida, bem como desencadeando a mutilação política de enfrentar essas próprias cargas e perdas, o que rebate nos movimentos sociais.

Ao procurar mediações mais profundas, foram localizados dois processos principais nas duas dimensões. O primeiro é relativo à origem cultural patrimonialista da política brasileira, conforme apresentada em Batista (1999). O segundo, mais universal, revela, no caso exemplo dos representantes dos conselheiros do CES analisado, camadas trabalhadoras difusas, diversificadas, fragmentadas e impregnadas da cultura de dominação, existindo uma grande distância para sua caracterização como classe para si (Marx, [1950], p. 168-169). Nessa realidade, estaria havendo uma "contradição de consciência [...], produzindo um estado de passividade moral e política" (Gramsci, 1977, p. 1583-1584, apud Simionatto, 1995, p. 43-44). Esse processo parece ocorrer dentro de uma mistura difícil com o "primeiro momento econômico-corporativo" dos representantes do ex-Consest-RJ, visto por Gramsci, 
contendo "a unicidade homogênea do grupo profissional e o dever de organizá-la, mas não ainda a unicidade do grupo social mais amplo", e, portanto, uma "não passagem da subalternidade à hegemonia" (Idem). Pelo tempo transcorrido da época de Marx e de Gramsci, verifica-se, portanto, a dificuldade de superar no tempo a cultura da dominação, apesar dos lampejos de possibilidades de mudança.

Nessa perspectiva, conclui-se que existe um processo contraditório conflituoso no interior da população trabalhadora nas instâncias de controle social democrático. Em vez de um consenso da classe trabalhadora, conforme a perspectiva de Gramsci, apresentada em Simionatto (Idem), vislumbrada na pesquisa em 1997, está sendo evidenciado um dissenso, por falta de uma direção intelectual e ética, bloqueando as conquistas políticas, no sentido de ultrapassar a subalternidade, base para a conquista da hegemonia. No interior da instituição pública investigada, essa direção é também prejudicada pelas contradições na própria organização e relações sociais ali presentes, agravada pela contrarreforma do Estado e reestruturação neoliberal dessas relações.

Entretanto, a despeito dessas contradições, das dificuldades e dos retrocessos ocorridos, os mecanismos de controle social, na dialética de espaços contraditórios, mobilizando trabalhadores organizados, população e intelectuais da área de saúde do trabalhador, já confirmaram a validade dessa via para construção da contra-hegemonia. Embora restritos e muito manipulados nos locais de trabalho e nas comunidades, pelas estratégias empresariais neoliberais e cultura patrimonialista, demonstraram, até 1997, seu potencial político, sobretudo fora dos locais de trabalho. Contudo, ele ainda apresenta relativa dependência da direção política governamental, necessitando fortalecer-se, sobretudo na articulação com os movimentos sociais e organizações mais autônomas de trabalhadores, a fim de superar as contrarreformas, as diferentes culturas dos segmentos e a competitividade destrutiva entre eles.

Nessa fusão complicada, determinada, de um lado, pelo avanço dos espaços conquistados por intelectuais e sindicalistas, e, de outro, apropriados pela cultura dominante, coloca-se "a necessidade da relação teoria-prática, da relação intelectuais-massa” (Simionatto, 1995, p. 44). ${ }^{20}$ Ela se iniciaria com “a compreensão crítica de si [para constituir], uma luta de hegemonias, primeiro no campo da ética, depois da política, para atingir uma elaboração superior da própria concepção do real" (Gramsci, 1977, p. 1583-1584, apud Simionatto, 1995, p. 44). Nesse sentido,

20. Segundo a mesma fonte teórica, são enfatizados os papéis dos sindicatos e dos partidos da classe trabalhadora, também enfrentando hoje o redemoinho neoliberal. 
o trabalho de assessoria nessa área, pelas universidades e centros de pesquisa, é fundamental e prioritário, merecendo apoio das agências de fomento, de modo similar a projetos vinculados às demais tecnologias, na direção contra-hegemônica da valorização de uma esfera pública democrática e do consenso crítico da classe que vive do seu trabalho.

Nesse sentido, para o desenvolvimento desse consenso, é essencial construir uma identidade ampliada de classe, para formação de uma consciência que tenha como centro a reflexão sobre a questão das relações sociais de trabalho, questão esta que afeta todos os que vivem do seu trabalho, estando na base da destruição da saúde de todos os trabalhadores e da natureza, da precariedade das condições de vida da maioria da população brasileira e do consumidor, bem como da violência visível nos crimes praticados, inclusive os ambientais. Nesse sentido, conclui-se que há necessidade de um longo processo de maturação, para maior qualidade do processo de politização. Este inclui a análise das opções políticas além das aparências e da mídia dominante, desde as relações nas instituições até o intercâmbio entre os países, pela via dos fóruns e instâncias de controle social.

Como fazer para alcançar esse objetivo? As diretrizes do projeto ético-político dos assistentes sociais brasileiros e de suas produções nessa direção encaminham-se nessa perspectiva. Contudo, os dados obtidos nos planos de trabalhos solicitados de alunos e profissionais de diversos níveis indicam ainda sua impregnação da lógica tradicional elitista, não suficientemente democrática, correspondente àquelas diretrizes. Embora a maioria reproduza os discursos críticos avançados e de controle social presentes na literatura crítica, predominam as estratégias e os procedimentos limitados à socialização de informações, às vezes para uma discussão futura em grupo, assim como palestras e debates posteriores a seminários. São processos importantes, extremamente válidos, mas que não deveriam ser únicos nem iniciais, de preferência, porque ainda são verticais, ou seja, de quem sabe mais para quem sabe menos, mantendo portanto a subalternidade.

O trabalho dos assistentes sociais com as mediações, proposto por esta autora (Freire, 1998a e 2003), oferece um caminho, porém não tem sido suficientemente incorporado nos referidos planos de trabalho. Por esse motivo, reapresento a possibilidade de ruptura das práticas conservadoras e sua operacionalização, nos três sentidos de mediação propostos:

O primeiro é o reflexivo na busca das mediações ontológicas, pelo assistente social como pesquisador, ou seja, na busca dos vínculos das situações presentes [demandas] 
no exercício profissional com os processos existentes nas totalidades universal, particular e singular, no sentido da apropriação da realidade concreta. O segundo sentido é o reflexivo como educador, com os sujeitos assessorados [ou atendidos] pelo assistente social ${ }^{21}$ ele se dá a partir das percepções desses sujeitos sobre as demandas trazidas, buscando a ultrapassagem das aparências dessas demandas, na busca das contradições e dos processos ocultos, procurando captar as relações dessas demandas com as particularidades e as totalidades que com elas se articulam; este sentido inclui a análise dos meios e formas dos sujeitos agirem nesta realidade, assim como a descoberta de outros meios e formas de ação possíveis. ${ }^{22} \mathrm{O}$ terceiro sentido é o do estímulo ao desencadeamento, pelos sujeitos, de processos determinantes, em suas ações na sociedade, que denomino mediações de prática social. $\mathrm{O}$ assistente social exerceria aí o papel de assessor no planejamento das ações pelos sujeitos e seu acompanhamento, de acordo com a correlação de forças, também objeto de análise, e em articulação com mecanismos políticos coletivos, internos e externos à instituição (que compreendem outras instituições, organizações comunitárias, sociedade civil organizada, já identificados no segundo sentido). (Freire, 2003, p. 137-138)

Embora essa proposta possa parecer por demais ampla e diferenciada da maioria dos procedimentos mais conhecidos, ela foi aplicada em dezenas de situações, não apenas por mim como profissional, desde 1973 (cf. Freire, 1987 e 2006). Também foi identificada, de modo similar, em outros trabalhos de assistentes sociais e não assistentes sociais, como o realizado com as câmaras técnicas do Consest-RJ até 1997. O requisito principal para sua operacionalização é o de uma metodologia usuário-centrada, possuindo nesse sentido afinidade com as tecnologias defendidas por Mehry (2006). Nesse sentido, é importante que os sujeitos atendidos e seus modos de sentir, pensar, imaginar, criar, agir, sejam estimulados em primeiro lugar, no segundo sentido da mediação. Sua assessoria consiste em apresentar questões sobre esse pensar e agir (por entrevista, questionário ou dinâmica de grupo), buscando seu aprofundamento, contradições, processos ocultos, com os porquês em cima de respostas, fatos e resultados apresentados. Tudo isso, evidentemente, em um clima de máximo respeito,

21. Tenho utilizado a ação de assessorar todos os sujeitos atendidos pelo Serviço Social, no sentido de expressar, de forma mais contundente, a perspectiva democrática de respeito à capacidade desses sujeitos de pensar sobre a sua realidade e elaborar seus planos de ação. Nesta perspectiva, o verbo assessorar substitui os verbos assistir, atender, apoiar, encaminhar, bem como a maioria dos compreendidos na ação profissional, na perspectiva de ruptura com o conservadorismo.

22. Esse segundo sentido constitui uma das particularidades do trabalho do assistente social com os sujeitos usuários (indivíduos, pequenos grupos, grupos representativos como comissões, conselhos e similares). A pesquisa analisa as posições colocadas, no plano da singularidade e das percepções subjetivas sobre as situações objetivas do cotidiano, muitas delas vividas em contextos societários. 
acolhimento e empatia, próprio dos princípios de relacionamento desenvolvidos no Serviço Social, valorizando as relações “intercessoras”, conforme Merhy (2002), nas quais há uma troca e construção de conhecimentos complementares entre o usuário e o prestador do serviço. Esse requisito inicial presta-se a todas as abordagens de atendimento possíveis: individual, grupal, institucional, comunitária e societária, junto a representantes de comissões, conselhos e similares.

Porém a oportunidade de maior expansão de alcançar os três sentidos de mediação apontados insere-se na metodologia de pesquisa-ação participativa e suas variantes, apresentada em diversas produções (Freire, 1987, 1998a, 2003 e 2006). Embora os princípios e diretrizes dessa metodologia possam ser aplicados nas demais abordagens, na pesquisa-ação eles têm oportunidade de ser mais bem explorados. No texto sobre assessoria a gestores e trabalhadores (Freire, 2006, p. 191), esse procedimento é enfatizado nos três sentidos de descoberta e criação de mediações, como pesquisador daquela realidade junto com os seus integrantes, coordenando "o processo educativo de levantamento e reflexão sobre necessidades e meios para atendê-las, de propostas de mudanças e de melhorias pelos usuários, cujos dados e análises se tornam, ao mesmo tempo, fonte de pesquisa", podendo prosseguir no planejamento e no acompanhamento da execução dessas propostas.

Nessa relação assistente social-usuários, podem ser desenvolvidos os seguintes processos (Freire, 2006, p. 193-195), utilizando triangulação de técnicas, como entrevistas, questionários, folders informativos, reuniões, seminários: a) discussão da demanda, com gestores e/ou usuários, apresentando um projeto/proposta de trabalho; b) mobilização de todos os integrantes da instituição ou determinado grupo para o qual foi identificada a necessidade do trabalho ou com indivíduos, como no caso de exames periódicos de saúde, ao se pretender realizar um trabalho posterior com representantes das áreas mais sujeitas a desgaste, ou de todas as áreas, por meio de uma comissão ou comissões de saúde, por exemplo; c) procedimentos democráticos para escolha de representantes, discutidos com todos; d) discussão dos objetivos, em grupo, comissão ou equivalente, a partir do entendimento do objeto do trabalho (expressão da questão social instalada ou latente) ${ }^{23} \mathrm{e}$ )

23. Os objetos são construídos a partir das demandas manifestadas, que não devem ser negadas de início, das mais aparentemente simples às mais complexas: atividades festivas e culturais; visitas de familiares; acidentes e doenças profissionais; absenteísmo; dependência química; atendimento em unidades de saúde, mesmo em emergência, com familiares; o próprio trabalho profissional, que poderá incluir assessoria a assistentes sociais e a outros profissionais, no caso de reestruturações, novos processos ou situações críticas nas instituições; o entendimento da instituição e dos processos que estão acontecendo nela na análise insti- 
descoberta de meios, limites e possibilidades, em instâncias externas à instituição; f) propostas de melhorias e mudanças, com negociação e acompanhamento sob controle social, podendo constituir-se uma comissão permanente.

Metodologicamente, o processo deve respeitar o ritmo e o conhecimento dos sujeitos, porém estimulando-os a ir além:

[... das] primeiras ideias [que] podem ser falsas ou incompletas percepções imediatas, [...] para se aprofundar o que estaria por trás delas. O que está por trás são mediações ou processos que articulam aquelas formas imediatas a processos maiores, particulares da instituição, da política pública, do Estado, da sociedade civil, do país, do mundo, com seus interesses e correlações de forças econômicas e políticas e meios culturais de dominação e de resistência. Isso seria captado na reflexão conjunta e por levantamentos e debates entre os integrantes do coletivo, para tornar possível a ultrapassagem do senso comum ou a apropriação relativa do concreto como "concreto pensado". (Marx, 1982, p. 14, apud Freire, 2006, p. 194)

Nesse momento, após o estímulo a todo o saber do grupo, são muito oportunos os seminários, cursos e similares, a serem também programados democraticamente nas ações propostas por ele.

No processo, é importante alcançar as relações das demandas além da instituição, com:

as estruturas e conjuntura da sociedade, não se encerrando o processo na apresentação de queixas, descoberta de necessidades e muito menos na expectativa de que a assessoria vai produzir soluções mágicas ou apenas mudar comportamentos de conflito para comportamentos de compreensão (que representaria uma outra perspectiva, não condizente com o projeto democrático e ético do assistente social). (Freire, 2006, p. 194-195)

A partir daí ainda há um longo caminho, mais difícil até, porque busca atingir a prática social, colocado como o terceiro momento de mediação. Ele avança na criação de propostas possíveis, com o grupo/comissão/conselho, nas realidades

tucional; necessidades e projetos de organizações comunitárias, em programas comunitários, como os habitacionais e até de "responsabilidade social" rediscutidos, por exemplo; conselhos, no entendimento do seu papel, das políticas e ações consequentes; ações de vigilância nas empresas por conselheiros e movimento sindical (cf. Freire, 1987 e 2006). 
analisadas e depois nas ações, que podem desencadear novos processos contraditórios. Para isso, poderão ser adotados procedimentos de planejamento, considerando: meios, limites, bloqueios e alianças possíveis com instâncias internas e externas de pressão e controle social; modos possíveis de interação, incluindo negociação, instâncias políticas, legislações e seu acompanhamento (Idem, p. 195).

O caminho é permanente, sempre inacabado porque dialético. Nele é importante, também, manter a própria capacitação continuada, como verificado na pesquisa com assistentes sociais (cf. Freire, 2003). Vinculado à sistematização do próprio trabalho, esse caminho percorre múltiplas mediações, que alimentam e enriquecem o saber profissional e a profissão.

\section{Artigo recebido em fev./2010 aprovado em mar./2010}

\section{Referências bibliográficas}

BARBIER, René. A pesquisa-ação na instituição educativa. Rio de Janeiro: Zahar, 1985.

BATISTA, A. Reforma do Estado: uma prática histórica de controle social. Serviço Social \& Sociedade, São Paulo, n. 61, p. 63-90, nov. 1999.

BRASIL. Ministério da Saúde. Portaria n. 1.679/2002. Rede Nacional de Atenção Integral à Saúde do Trabalhador — Renast. Brasília, 19 set. 2002.

Portaria n. 1.068, de 4 de julho de 2005a.

. Portaria n. 2.437, de 7 de dezembro de 2005b.

. RENAST. Manual de Gestão e Gerenciamento. Brasília/DF, 2006a.

. Documento base. 3. ed. In: Política Nacional de Humanização. Brasília/DF, 2006b. p. 15-32.

BRAVO, Maria Inês S. Gestão democrática na saúde: o potencial dos conselhos. In: BRAVO, M. I. S.; PEREIRA, Potyara A. P. (Org.). Política social e democracia. São Paulo: Cortez; Rio de Janeiro: Uerj, 2001.

CESAR, Monica de J. A intervenção social das empresas no Brasil. In: FREIRE, L. M. B.; FREIRE, S. M.; CASTRO, A. T. B. (Org.). Serviço Social, política social e trabalho. São Paulo: Cortez, 2006. p. 183-201.

. "Empresa-cidadã": uma estratégia de hegemonia. São Paulo: Cortez, 2008. 
COSTA, Cláudia de O. B. Readaptar ou reconstruir o trabalho público? Um estudo em um hospital universitário. 2006. Dissertação (Mestrado em Serviço Social) — Universidade do Estado do Rio de Janeiro, Uerj, Rio de Janeiro.

COSTA, M. Dalva H. C. Os serviços na contemporaneidade: notas sobre o trabalho nos serviços. In: MOTA, A. E. (Org.). A nova fábrica de consensos. 4. ed. São Paulo: Cortez, 1998. p. 97-113.

COUTINHO, Isis P.; MELLO, Ana Inês S. C. de; FREIRE, Lúcia M. de B. Assessoria à implantação e ao desenvolvimento da Política Nacional de Humanização no Hospital Universitário Pedro Ernesto. $20^{a}$ UERJ sem muros. Rio de Janeiro: UERJ, 2009. p. 182.

DIAS, Elizabeth C. A organização da atenção à saúde no trabalho. In: FILHO, M. F. (Org.). Saúde no trabalho. São Paulo: Rocca, 2000.

; HOEFEL, M. da Graça. O desafio de implementar as ações de saúde do trabalhador no SUS: a estratégia da Renast. Ciênc. Saúde Coletiva, v. 10, n. 4, p. 817-827, dez. 2005.

DIESAT. Insalubridade: morte lenta no trabalho. São Paulo: Oboré, 1989.

FERREIRA, Luciana A. Os exames periódicos de saúde (EPS) em um contexto de contrarreforma: entre concepções e práticas de intervenção profissional. 2007. Trabalho de Conclusão de Curso (graduação em Serviço Social) — Universidade do Estado do Rio de Janeiro, Rio de Janeiro.

FREIRE, Lúcia M. de B. Serviço Social organizacional: teoria e prática em empresa. São Paulo: Cortez, 1987.

Saúde do trabalhador e Serviço Social: possibilidades pelo avesso do avesso. 1998a. Tese (Doutorado em Serviço Social) — Pontifícia Universidade Católica de São Paulo, São Paulo.

. O Serviço Social e a saúde do trabalhador diante da reestruturação produtiva nas empresas. In: MOTA, A. E. (Org.). A nova fábrica de consensos. São Paulo: Cortez, 1998b. p. 167-194.

O Serviço Social na reestruturação produtiva: espaços, programas e trabalho profissional. São Paulo: Cortez, 2003.

Assessoria e consultoria a gestores e trabalhadores como trabalho do assistente social. In: BRAVO, M. I. S.; MATOS, M. C. de. Assessoria, Consultoria \& Serviço Social. São Paulo: Cortez, 2006. p. 184-203.

FREIRE, Lúcia M. de B.; FERREIRA, Aline de J.; WARDINE, Jurema F. Avanços e retrocessos nas ações de controle social na área da saúde do trabalhador: um estudo do 
Consest-RJ. IX ENPESS — Encontro Nacional de Pesquisadores em Serviço Social, 9. ABEPSS - Associação Brasileira de Ensino e Pesquisa em Serviço Social. Porto Alegre, 2004. 1 CD-ROM.

LAURELL, Asa Cristina; NORIEGA, Mariano. Processo de produção e saúde: trabalho e desgaste operário. São Paulo: Hucitec, 1989.

MARX, Karl. Miseria de la filosofia. Moscou: Ediciones en Lenguas Extranjeras, [1950].

MERHY, Emerson E. A cartografia do trabalho vivo. São Paulo: Hucitec, 2002.

Um dos grandes desafios para os gestores do SUS: apostar em novos modos de fabricar os modelos de atenção. In: MERHY, Emerson et al. $O$ trabalho em saúde: olhando e experenciando o SUS no cotidiano. 3. ed. São Paulo: Hucitec, 2006. p. 15-35.

NETTO, José Paulo. Para a crítica da vida cotidiana. In: NETTO, José Paulo; FALCÃO, Maria do Carmo. Cotidiano: conhecimento e crítica. São Paulo: Cortez, 1987.

PORTO, Marcelo F. de S. Acidente químico cobre Baixada Fluminense com nuvem tóxica e mata operários. In: MIRANDA, M.; WEID, N.; LOUREIRO, C. F. (Org.). Ambientes de trabalho, ambientes de vida: capítulos da poluição industrial no Rio de Janeiro. Rio de Janeiro: Ibase, 2000. p. 12-15. (Justiça Ambiental, v. 1.)

SIMIONATTO, Ivete. Gramsci: sua teoria, incidência no Brasil, influência no Serviço Social. Florianópolis: Daufsc; São Paulo: Cortez, 1995.

VASCONCELLOS, Luiz C. F. de. Saúde, trabalho e desenvolvimento sustentável: apontamentos para uma política de Estado. 2007. 417 f. Tese (Doutorado em Saúde Pública) — Escola Nacional de Saúde Pública Sérgio Arouca (Ensp), Fundação Oswaldo Cruz (Fiocruz), Rio de Janeiro.

; RIBEIRO, Fátima S. N. A organização dos serviços de saúde do trabalhador sob o prisma epidemiológico e de controle social: avaliação das práticas do Rio de Janeiro (Brasil) no período de 1992-1994. Rio de Janeiro, 1994.

; _ـ Investigação epidemiológica e intervenção sanitária em saúde do trabalhador: o planejamento segundo bases operacionais. Cad. Saúde Pública, v. 13, n. 2, p. 269-275, abr. 1997.

WARDINE, Jurema F. Entre a cura e o adoecimento: trabalho e desgaste mental entre auxiliares de enfermagem do centro cirúrgico de um hospital universitário. 2004. Monografia de Conclusão de Curso (Graduação em Serviço Social) — Universidade do Estado do Rio de Janeiro, Rio de Janeiro. 